\title{
Engaging students in critical thinking: A student's perspective of family nursing in the intensive care unit
}

\author{
Jessica H. Conway, Linda Yetman \\ University of New Brunswick, Saint John, Canada \\ Correspondence: Dr. Linda Yetman. Address: PO Box 5050, University of New Brunswick, Saint John, NB, Canada E2L \\ 4L5. Email: lyetman@unb.ca.
}

Received: August 30, 2012

Accepted: October 17, 2012

Online Published: January 5, 2013

DOI : 10.5430/jnep.v3n6p111

URL: http://dx.doi.org/10.5430/jnep.v3n6p111

\begin{abstract}
The authors of this article propose that nurse educators engage students in ways to 'think family' so that family nursing can be incorporated into care with appropriate nursing interventions. While in-depth family-centered care requires advanced post-graduate education, attention to five areas of family needs: information, proximity, assurance, support and comfort, during undergraduate education will enable students to continue family nursing into their clinical practice and help decrease family anxiety associated with a relative's illness. Nurse educators have a responsibility to teach in ways that foster curiosity to 'test' application of theoretical concepts into clinical practice.
\end{abstract}

\section{Key words}

Nursing student, Family nursing, Student engagement, Intensive care unit

\section{I ntroduction}

The role that families acquire in providing support, care and assistance for critically ill patients is increasing ${ }^{[1]}$. Consequently, nurses are expected to support families in this role and provide strategies for families to participate in care in meaningful ways. Family-centered care has been defined as "an innovative approach to the planning, delivery, and evaluation of health care that is grounded in mutually beneficial partnerships among health care patients, families and providers” ${ }^{[2]}$. And, whereas family-centered care may contribute to nurses' satisfaction with clinical practice, nursing curricula need to incorporate more family nursing content in order to effectively prepare nurses to care for families in the challenging clinical settings in which they will find themselves upon graduation ${ }^{[3]}$. While the role of the nurse educator is multi-faceted, a key element of the role is to engage students in ways to integrate the theoretical knowledge into clinical practice and to do so in ways that will foster creative thinking and clinical reasoning to positively impact healthcare delivery. To prepare future nurses, nurse educators must implement teaching strategies that provide experiences for the student to integrate "knowledge, skilled know-how, and ethical comportment" ${ }^{[4]}$. The authors of this article propose that knowledge related to family nursing needs to be taught in a way to stimulate a sense of knowing in particular clinical situations that will help students to integrate classroom theory and clinical experiences with positive impact on familynurse interactions. 


\section{Teaching for a sense of knowing}

Benner et al. ${ }^{[4]}$ propose that nursing education ought to provide more effective ways to increase the three major areas of professional development, knowledge, skilled know-how, and ethical comportment. In order to expand these areas and promote true integration of theoretical knowledge and clinical practice, they suggest that four essential shifts must occur. These shifts are:

1) A focus on covering decontextualized knowledge to an emphasis on teaching for a sense of salience, situated cognition, and action in particular situations;

2) A sharp separation of clinical and classroom teaching to integration of classroom and clinical teaching;

3) An emphasis on critical thinking to an emphasis on clinical reasoning and multiple ways of thinking that include critical thinking;

4) An emphasis on socialization and role taking to an emphasis on formation ${ }^{[4]}$.

The second author of this article is a nurse educator who has significant clinical expertise as an Advanced Practice Nurse (APN) where family nursing has been held as central to care delivery. In teaching an undergraduate (third year) family nursing classroom course for the first time and following a review of the literature related to effective teaching strategies, two questions emerged repeatedly:

- How can this course be taught so that it is clinically relevant?

- How can students be encouraged to 'think family'?

Building on Benner et al.'s ${ }^{[4]}$ suggestions above, the course was designed with a focus on the first two shifts to occur during the course delivery.

\subsection{Family nursing in curricula}

Implementing family nursing into clinical practice bears its challenges in clinical settings world-wide ${ }^{[5]}$. Green suggested that teachers must put an emphasis on designing questions for students that will foster systems thinking ${ }^{[1]}$ and more work is required to adequately prepare students for family nursing in their work environments ${ }^{[3]}$. Respecting the advances in research related to family nursing, the integration of families / family nursing into an individual nurse's care remains problematic for most nurses and certainly for nursing students who receive basic education related to family nursing. Many of these challenges are related to the complexities associated with the illness of the patient and compounded by the interdependent relationships that exist between family members as they cope with family dynamics and individual 'relationships' to the patient's illness / injury ${ }^{[5,6]}$. Family nursing content has existed in nursing curricula for well over two decades; however, there is wide variation in the content and delivery of that content ${ }^{[3]}$. Furthermore, undergraduate nursing students learn to work with families at a basic level with graduate nursing education providing more in-depth knowledge to prepare nurses to intervene at an advanced level with families. However, given the rise in patient acuity and the increased role that families are acquiring in providing support and care, it stands to reason that the registered nurse without advanced preparation in family nursing will be required to provide family nursing interventions in their clinical practice..In addition, not all clinical settings have APNs with in-depth education related to family nursing. Consequently, nurse educators must be creative and embed at least a beginning curiosity in undergraduate students to 'think family'. In theory, a nurse may view family nursing from a specific level depending on their developing knowledge and experience. Friedman, Bowden and Jones ${ }^{[7]}$ provide a model of five levels of family nursing:

1) A social context of the individual patient;

2) The sum of its parts;

3) A subsystem - primary focus is assessment and care; 
4) A system where the entire family is viewed as the client;

5) As a system as a system within a larger system ${ }^{[7]}$.

St John and Flowers make a crucial point in their statement, "How a nurse conceptualizes and works with a family is influenced by their expertise and the philosophy and structures of their practice environment” ${ }^{[3]}$. Therefore, the first question that occurred while designing the course of 'How can this course be taught so that it is clinically relevant?' is, in part, answered by taking into consideration the diversity of clinical settings in which the majority of these students will practice upon graduation. Content coverage needed to include the basic concepts of family nursing to guide their clinical practice to incorporate the family into their care no matter where they will practice. For the purposes of this first time delivery of the course, the content was designed to cover the basic theoretical concepts. Information related to the importance of family assessments was taught, however not at an in-depth level that students would be expected to conduct these assessments within the role of a baccalaureate prepared nurse; one particular model was not taught. Rather, a variety of teaching strategies such as clinical exemplars, case studies, role playing and student presentations were used to cover the content and to expose students to salient areas in family nursing as well as to encourage dialogue about topics such as families in crisis, families adjusting to illness / injuries, families experiencing chronic illnesses and associated family nursing interventions. In addition, written assignments were requested. Students could explore topics of their choice as long as they pertained to a family nursing concept. These strategies are in keeping with those proposed in the literature by family nursing scholars that help to prepare nursing students to care for families at a beginning level ${ }^{[8,9]}$.

\subsection{Engaging students to 'Think family'}

Green's work ${ }^{[1]}$ was drawn upon to help with the question of 'How can students be encouraged to 'think family'?' Many of the strategies outlined above were used throughout the course delivery for student engagement. However, three main strategies were used to encourage students to 'think family'. First of all, an email was sent to all clinical teachers from the classroom teacher to highlight which topics related to family nursing were covered in class and to seek support from those teachers to encourage the students to 'think family' while in the clinical areas. There were definitely times when students would not encounter families visiting because of the hours of clinical practice for the students. However, feedback from the clinical teachers suggested that they appreciated the email and they tried to encourage the students to integrate family nursing interventions where possible. Secondly, each week at the beginning of class, the students were asked to recount any experiences that they had with families. These experiences were described and the teacher and entire class engaged in a dialogue about these experiences. What worked, what didn't work with respect to family nursing interventions were explored. Ideas were generated for application of interventions for students who were involved in other clinical specialties. For example, if a group of students on a cardiac rotation reported on a family situation and family nursing interventions, would the same interventions work with families in neurotrauma, orthopedics or oncology? These discussions provided a rich essence to the course. Debates occurred, values and beliefs surfaced that needed to be explored. These discussions, by far, helped the students to 'think family'. Thirdly, structured feedback on assignments and involving students in individual conversations about the content of their assignments and whether they wanted to pursue more thorough analysis of their topic for application in the clinical area generated some interest in students. The first author of this article sought out a clinical experience in the clinical rotation following the end of her family nursing course in order to test some of the concepts she had learned about and wanted to apply. The content presented later in this article is the work as viewed from a student's family nursing lens.

\section{Family nursing from a student's perspective}

\subsection{Background}

As part of a surgical rotation in the third year of a baccalaureate nursing program, the primary author of this article had the opportunity for a clinical practice experience in a 12-bed surgical intensive care unit (SICU) of a 445 - bed tertiary care 
hospital. This section of the article describes one patient / family situation where theoretical content from the classroom was applied in that setting.

\subsection{Case study}

Following a diagnosis of esophageal cancer, Mr. B, 75 years old, was admitted to the SICU following a complication from a surgical procedure to remove a tumour from his esophagus. A fistula formed from his gastroesophageal junction to his left main bronchus. This complication caused bile from his stomach to enter his lungs. The patient was sedated and ventilated and required a jejunostomy tube for feedings and a nasogastric tube on suction. The tubes connecting to the ventilator had to be emptied several times a day because bile would collect in them. The patient's past medical history included chronic obstructive pulmonary disease and hypertension.

Mr. B was married with six children and a large extended family. The wife and many family members kept a bedside vigilance during the patient's SICU stay.

\subsection{I mportance of family nursing in the SICU}

While providing excellent family nursing within the ICU setting has lasting effects on the family's well-being, Vandall-Walker, Jensen and Oberle ${ }^{[10]}$ suggest that there are several negative effects that families may experience when they have a family member in the ICU. For example, families have reported feelings of helplessness and hopelessness. One implication these negative effects have on the family members has contributed to suppressing the family member's immune systems ${ }^{[11]}$. If family members do not receive the support they need they may develop feelings of intense emotional distress including post-traumatic stress disorder after their relative's death or discharge from the ICU ${ }^{[10,11]}$. Therefore, while family members can be an important support system to the patients while they are in the hospital, this support may become compromised if the family becomes psychologically distressed ${ }^{[11]}$. According to Karlsson et al, "On an institutional level understanding patients' and families' experiences can provide a foundation for improving nursing services" ${ }^{[12]}$. Drawing on the literature in order to understand the family's experience of Mr. B and seeing the family 'as context' ${ }^{[7]}$ as he moved through his SICU experience, the first author drew on concepts learned in the family nursing course in order to implement family nursing with this patient and family.

\subsection{Five domains of family needs}

Leske ${ }^{[13]}$ identified five domains of family needs when a relative is experiencing a critical illness:

- Information

- Proximity

- Assurance

- Support

- Comfort

Responding to these needs within the context of Mr. B's family provided a rewarding and satisfying experience of family nursing for this nursing student.

\subsubsection{Need for information}

Providing the patient's family with accurate and up-to-date information is essential when providing care to the family ${ }^{[14]}$. When a family is unsure or unaware of what is happening with their loved one, this uncertainty can provoke unnecessary fear for the family members ${ }^{[14]}$. Family members need accurate and timely information regarding their relative's medical condition, treatment, interventions, changes in their condition ${ }^{[12]}$ and while at times, the future seems ambiguous, families seek some sense of what the future may hold. Each of Mr. B's family members were updated on his condition when they 
came to visit. And, while family members were particularly inquisitive about the patient's status and equipment, the main concern for the wife was related to her husband's medications. Explanations were offered; many explanations had to be repeated upon each visit. The family also requested to speak with the physician regarding Mr. B's care plan. They wanted to know what would happen in the event that he "did not make it.” A meeting with the physician was facilitated by explaining to the family that the request would be made when the physician made rounds. A follow-up with the family on the next shift confirmed that the family did speak with the physician who answered all their questions. The family expressed appreciation for the facilitation of the meeting as well as "checking in" to see if indeed they had spoken with the physician. Some literature suggests that information in the form of pamphlets, orientation to the unit, the ICU's policies and commonly used equipment greatly improves families' understanding of the patient's diagnosis, prognosis and treatment ${ }^{[11]}$. And, while some families who are asking questions or guidance about care may be perceived as demanding ${ }^{[12]}$, clarifying with the family when they were last updated and providing that 'status report' will often ease the anxiety and make for a comfortable visit with the patient.

\subsubsection{Proximity to the patient}

Despite the expressed need for families to be near their loved one, proximity may not be commonly practiced and nurses may not ask family members to stay during procedures or to participate in care ${ }^{[15]}$. If relatives are not included in care they may feel powerless and fearful ${ }^{[16]}$. These feelings of powerlessness and fear will lead to greater anxiety for family members and compromised physical and psychological well-being occur, as suggested by some authors ${ }^{[10,11]}$. The actions of Mr. B's nurses were congruent with the findings in the literature. Family members were asked to wait outside until 'care was completed'. However, Mr. B's sister did comb his hair and give foot rubs. Mitchell et al. ${ }^{[2]}$, examined the role of family members' involvement in care. Types of care that easily permit family participation include combing the patient's hair to assisting with a bed bath. Their findings suggested that patients' family members "perceived more respect, support, and collaboration than did the patient's family members who were not involved in the patients' care" ${ }^{[2]}$. Providing flexible visiting hours for family members may also help meet the needs of families; however, this flexibility is not commonly implemented in many facilities ${ }^{[16]}$. Cypress suggests that having flexible visiting hours in the ICU allows for flexibility for patients and families and could be determined on a case-by-case basis ${ }^{[17]}$. While visiting hours in the SICU could occur at any time (day or night), only immediate family could visit and for five to ten minute intervals and not during rounds. Family members were invited to participate in care (during the shifts of the first author) and it was visible that simple acts such as combing the patient's hair or giving foot rubs became meaningful to family members.

\subsubsection{Need for assurance}

Assurance is essential to families in an ICU setting. Family members need to feel security and trust from the nursing staff ${ }^{[12]}$. Introducing oneself as the nurse caring for the patient, responding promptly to alarms and requests for assistance as well as trying to explain the various alarms / noises in the setting helps to offer assurance to family members. Entering an ICU setting is alien for most people and oftentimes, healthcare professionals forget that what is 'normal' for them is a very unsettling and overwhelming experience for family members. Having learned about the importance of 'simple interventions' such as introducing oneself, this was a strategy used each shift by the first author. In addition, observations were made to see if other staff members introduced themselves and it was a common practice in this setting for introductions to occur and family members seemed to quickly know staff as well as to seem at ease to ask questions. On one occasion, when the patient's wife seemed particularly upset and remained at a distance, a soft encouragement to her, guidance to the bedside and gently placing the patient's hand in her hand seemed to be the needed intervention. Such as simple intervention - the reaction from the wife was relief that she could do this!

\subsubsection{Needs for support and comfort}

Family members feel supported when nurses are available for daily conversations and also appreciate the ability to be able to call the unit at any time to check in on their relative ${ }^{[12]}$. During this clinical rotation, there were ample opportunities to have conversations with Mr. B's family members. In the role of a student nurse, these opportunities are times to practice any areas that are uncomfortable with family interactions with the guidance of a staff nurse mentor or clinical teacher. 
Two areas that have been identified in the literature as needs for support and comfort are when the patient moves out of the ICU setting and having comfortable waiting rooms ${ }^{[12,15]}$. In today's chaotic clinical settings, families are frustrated when patients are moved and often at inconvenient times. Families may feel unprepared and abandoned. Mr. B was not transferred during this clinical rotation and given the fact that it was unlikely to occur in the very near future, conversations regarding a transfer did not arise. Conversations about the immediate family needs for support and comfort were the focus. Provision of comfortable waiting rooms has been identified as a need for families ${ }^{[12]}$. However, families are often compressed into small areas without privacy. Many facilities simply cannot provide spacious rooms that allow for privacy. Therefore, attending to the family needs for support and comfort through meaningful conversations becomes even more crucial so that families can "feel" emotionally supported without the physical feel and support of a comfy couch.

\section{Conclusion}

Any hospitalization is most likely stressful for both patients and their families. Hospitalization in an ICU setting bears a unique set of stressors for patients and their families. Incorporating family nursing into the overall patient care is essential. However, concepts of family nursing are not well integrated in all nursing curricula. Teaching strategies must be well thought out to help students develop a curiosity to test out in clinical practice what is taught in the classroom. In doing so, nursing students develop their family nursing interventions and become prepared for what may be possible versus entering into a 'status quo' clinical environment. Nurse educators owe their students a rich teaching -learning experience in ways that offer clear directions to instill optimism and confidence in their student years that will carry them into their clinical practice as nurses and future mentors for the next 'student'. This article has offered a review of five areas of needs of families. Though interventions associated with these areas are simple, oftentimes, it is the simplicity that is most powerful.

\section{References}

[1] Green CP. Teaching students how to think nursing. Journal of Family Nursing.1997; 3(3): 230-246. http://dx.doi.org/10.1177/107484079700300302

[2] Mitchell M, Chaboyer W, Burmeister E \& Foster M. Positive effects of a nursing intervention on family-centered care in adult critical care. American Journal of Critical Care. 2009; 18(6): 543-552. http://dx.doi.org/10.4037/ajcc2009226

[3] St John W \& Flowers K. Working with families: From theory to clinical nursing practice. Collegian. 2009; 16: 131-138. http://dx.doi.org/10.1016/j.colegn.2009.04.001

[4] Benner P, Sutphen M, Leonard,V \& Day ,L. Educating nurses: A call for radical transformation. JosseyBass, San Francisco, CA. 2010.

[5] Leahey M \& Kolbrun Svavarsdottir E. Implementing family nursing: How do we translate knowledge into clinical practice? Journal of Family Nursing. 2009; 15(4): 445-460. http://dx.doi.org/10.1177/1074840709349070

[6] Duhamel F. Implementing family nursing: How do we translate knowledge into clinical practice? Part II: The evolution of 20 years of teaching, research, and practice to a center of excellence of family nursing. Journal of Family Nursing. 2010; 16(1): 8-25. http://dx.doi.org/10.1177/1074840709360208

[7] Friedman MM, Bowden,VR, \& Jones EG (Eds.). 2003. Family nursing: Research, theory and practice. Upper Saddle River, NJ, Prentice Hall. 2003.

[8] Moules N \& Tapp D. Family nursing labs: Shifts, changes and innovations. Journal of Family Nursing. 2003; 9(1): 101-117. http://dx.doi.org/10.1177/1074840702239493

[9] Tapp, D, Moules, N, Bell, J, Wright, M. Family skills labs: Facilitating the development of family nursing skills in the undergraduate curriculum. Journal of Family Nursing. 1997; 3(3): 247-266. http://dx.doi.org/10.1177/107484079700300303

[10] Vandall-Walker V, Jensen, L, \& Oberle, K. Nursing support for family members of critically ill adults. Qualitative Health Research. 2007; 17(9): 1207-1218. http://dx.doi.org/10.1177/1049732307308974

[11] Bailey, JJ, Sabbagh, M, Loiselle,CG, Boileau, J \& McVey L. Supporting Intensive \& Critical Care Nursing. 2010 ; $26(2)$ : 114-122. http://dx.doi.org/10.1016/j.iccn.2009.12.006

[12] Karlsson C, Tisell A, Engström A \& \& Andershed B. Family members' satisfaction with critical care: a pilot study. Nursing In Critical Care. 2011; 16(1): 11-18. http://dx.doi.org/10.1111/j.1478-5153.2010.00388.x 
[13] Leske JS. Needs of adult family members after critical illness: Prescription for interventions. Critical Care Clinics of North America. 1992; 4: 587-596. ISSN: 0899-5885 PMID: 1288581

[14] Blanchard D \& Alavi C. Asymmetry in the intensive care unit: redressing imbalance and meeting the needs of family. Nursing in Critical Care. 2008; 13(5): 225-231. http://dx.doi.org/10.1111/j.1478-5153.2008.00292.x

[15] El-Masri M. \& Fox-Wasylyshyn S. Nurses' roles with families: perceptions of ICU nurses. Intensive \& Critical Care Nursing. 2007; 23(1): 43-50. http://dx.doi.org/10.1016/j.iccn.2006.07.003

[16] Buckley P \& Andrews T. Intensive care nurses’ knowledge of critical care family needs. Intensive \& Critical Care Nursing. 2011; 27(5): 263-272. http://dx.doi.org/10.1016/j.iccn.2011.07.001

[17] Cypress, B S. The lived ICU experience of nurses, patients and family members: A phenomenological study with Merleau-Pontian perspective. Intensive \& Critical Care Nursing. 2011; 27(5): 273-280. http://dx.doi.org/10.1016/j.iccn.2011.08.001 